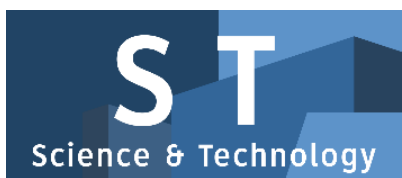

PAPER - OPEN ACCESS

\title{
Effect of Operation Condition on Gelugur Acid (Garcinia atroviridis) Drying Rate Using Tray Dryer
}

\author{
Author $\quad:$ R Hasibuan \\ DOI $\quad: 10.32734 /$ st.v1i2.293 \\ Electronic ISSN $\quad:$ 2654-7082 \\ Print ISSN $\quad$ :2654-7074
}

Volume 1 Issue 2 - 2018 TALENTA Conference Series: Science \& Technology (ST)

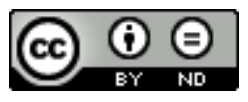

This work is licensed under a Creative Commons Attribution-NoDerivatives 4.0 International License.

Published under licence by TALENTA Publisher, Universitas Sumatera Utara
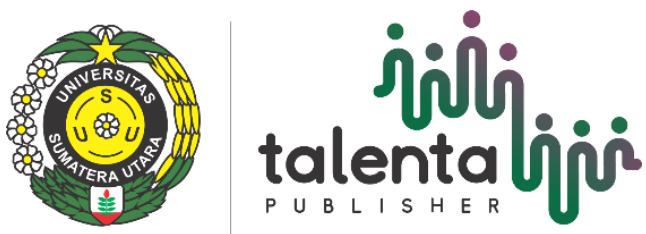


\title{
Effect of Operation Condition on Gelugur Acid (Garcinia atroviridis) Drying Rate Using Tray Dryer
}

\author{
R Hasibuan ${ }^{a^{*}}$, and Heri Gusman ${ }^{\mathrm{a}}$ \\ Chemical Engineering Department, Faculty of Engineering, Universitas Sumatera Utara, Medan, Indonesia
}

rosdanelli@yahoo.com

\begin{abstract}
Garcinia atroviridis is commodities with economic potential that is promising in the future, because it is not only used as spices dishes but lately it has become a necessity in cosmetic industry. One of the background of this research is due to the abundance of Garcinia atroviridis in North Sumatra. The post-harvest of processing Garcinia atroviridis as long as its done with conventional drying process, i.e.drying out directly under the scorching sun where it put on the sack or tarp and in the roads through which motor vehicles have some disadvantages such as:require a long drying time, not hygiene, contaminated by dust and sand, plaguedby animals and insects, as well as the uncertain weather circumstances. Therefore necessary the dryer could overcome these weaknesses by conducting a drying study of Garcinia atroviridis using tray dryer.Its consists of: a drying room equipped with a tray of dried material, air heater, fan, control panel of temperature gauge and relative humidity (RH).

The main purpose of this research was to study the influence of operating conditions against the rate of drying and characteristics of drying Garcinia atroviridis. This research was conducted by varying the drying temperature $\left(45 \mathrm{dan} 55^{\circ} \mathrm{C}\right)$ and varying air flow $\operatorname{rate}(1.15$ and $2.25 \mathrm{~m} / \mathrm{s})$, with a weight of Garcinia atroviridis first 500 grams. The drying is done by weighing each ingredient specified time interval until reaching constant weight. The results showed that the air flow rate and temperature affect the drying rate, where at temperature $55^{\circ} \mathrm{C}$ and flow rate $2.25 \mathrm{~m} / \mathrm{s}$ can lower the moisture content of $90 \%$ within 540 minutes.As for the characteristics of the drying Garcinia atroviridis generally showed there are only twostages of drying rate, that is the drying rate rises and the drying rate decline. But on the operating conditions of the air flow rate $1.15 \mathrm{~m} / \mathrm{s}$ and temperatures of $55^{\circ} \mathrm{C}$ showed three stage that is drying rises, constant and decline.
\end{abstract}

Keywords: characteristics of drying; Garcinia atroviridis; tray dryer

\section{Introduction}

Garcinia atroviridis contains citric acid, tartaric and ascorbic which has antioxidant activity. The extract can serve as a powerful antioxidant, antimicrobial, antitumor, and anti-inflammatory activity[1]. The economic potential is actually quite good. Currently the price of fresh fruit at the farm level ranges between Rp 5000/kg. While the price after thinly sliced and dried between Rp 25.000-28.000/kg.One kilogram of fresh fruit can produce 250 grams of exported dry acid quality[2]. 


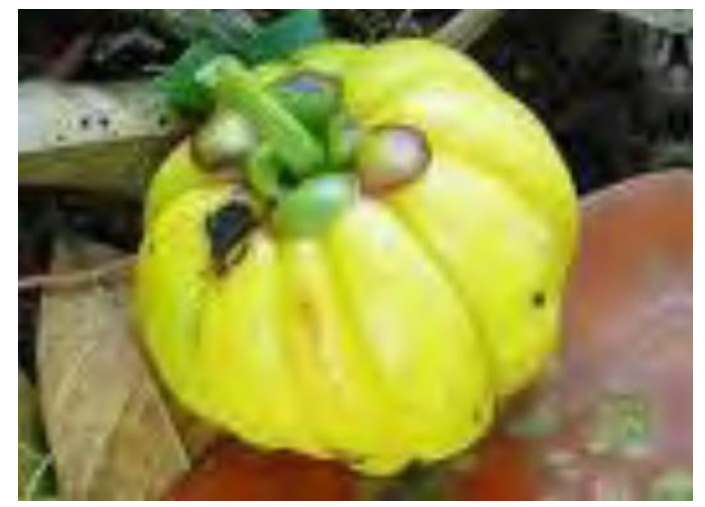

(a)

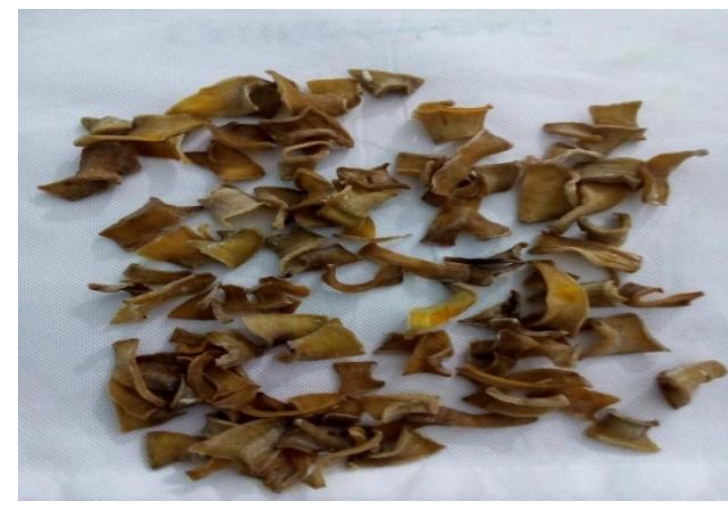

(b)

Fig. 1. (a) Fresh aruit of Garcinia atroviridis and (b) Dried Garcinia atroviridis

When harvestingfruit will risk a foul feast so that required a proper preservation methods, one of which was with drying.Garcinia atroviridis belonging to the family Gutiferae. In Indonesia it is known as gelugur acid or acid chip[1]. During this drying is done by way of drying out directly under the scorchingsun. How to direct drying out under the Sun is placed on a sack or tarp in the outdoors, so need an ample drying out, drying time is relatively long, level of cleanliness is not guaranteed, the constraints when it rained, plagued by insects, rodents, and other animals. To resolve the problems or obstacles faced by the farmers in the countryside then the researchers conducting study of drying Garcinia atroviridis using tray dryer by research the influence of operating conditions against the rate of drying and drying characteristics of Garcinia atroviridis using tray dryer.

\section{Materials and Methodology}

\subsection{Location Research}

The research was conducted at Operation Chemical Engineering Laboratory, Faculty of Engineering, University of North Sumatera.

\subsection{Methodology}

The raw materials used are gelugur acid (Garcinia atroviridis) from plantation in Deli Tua sub-district Deli Serdang District of North Sumatra.The instrument used is tool tray dryer, as shown in the picture 


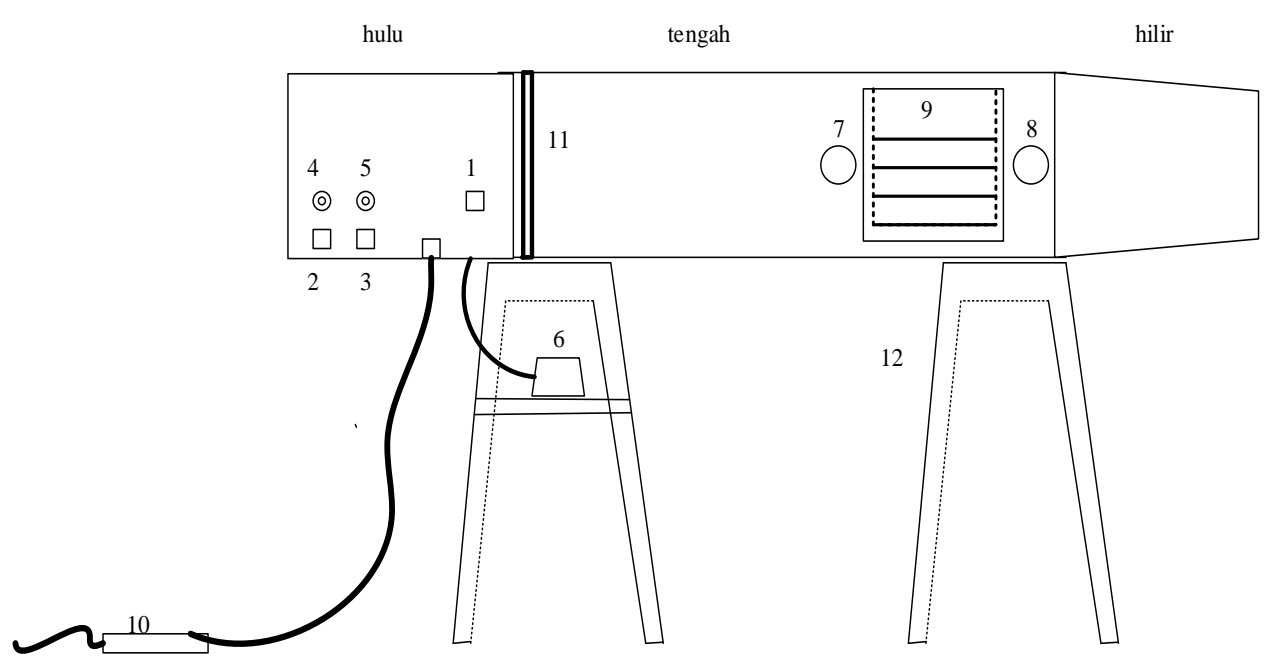

Fig 2. Tray Dryer

Description: (1)Meter supply button (2)Fan button(3)On/off button of Temperature control (4)Flow rate control switch (5)Temperature control switch (6)Psychrometer (7)(8)The place of thermometer (9)Drying room(10)Electric socket (11)Heater (12)Feet Dryer

\subsection{Procedure}

\section{Raw Material Preparation}

(1) Raw materials (Garcinia atroviridis) washed using water then drained, (2) Then cut it by $0.5 \mathrm{~cm}$ thickness (3) take a cut of 500 grams of Garcinia atroviridisand put on the tray,(4) take a cut of 100 grams of Garcinia atroviridis for analysis of initial moisture content (IMC).

Analysis initial moisture content (IMC)is to get the moisture content of Garcinia atroviridis firstly prior to drying process, by means of weighted as much as 100 grams of Garcinia atroviridis then put on the aluminum foil and dried in an oven at a temperature of $110 \pm 5^{\circ} \mathrm{C}$ for 24 hours.

\subsection{Operational Procedure}

The undertaken operational procedure is to vary the air flow rate at a constant temperature andvarying the temperature at a constant air flow rate:

(1) The raw material weighed 500 gr at first,(2) The material is placed on the tray and put in the dryer and then closed closely, (3) Switch On the tray dryer,(4)Rotated the temperature control knob and the air flow rate in accordance with the desired value where the temperature as a variable change that is on $\left(45\right.$ and $\left.55^{\circ} \mathrm{C}\right)$ andair flow rate $(1.15$ and $2.25 \mathrm{~m} / \mathrm{s})$, (5) The material is weighed every 10 minutes in the first hour and then weighed every 30 minutes until a constant material weight is obtained, (6) Procedures 1 to 5 are repeated for other variations.

\section{Results}

The initial result of gelugur acid water content (IMC) analysis was obtained between $90-91 \%$. Furthermore, the same method of analysis is used to calculate the material moisture content (MC) right after the drying process of the gelugur acid using tray dryer. 
In the drying process, moisture content is generally determined based on dry basis. More precisely, by comparing the weight of the wet and dry material, the moisture content can be determined. The calculation of the moisture content and the drying rate are performed by the equations derived [4].

Moisture Content (MC)

$$
I M C / M C=\frac{\text { wetweight }- \text { dryweight }}{\text { dryweight }}
$$

Krischer curve or curve that is not relying on the time is the drying rate curve vs. Moisture content [5]. Usually this curve is obtained from the combination of the drying curve and the curve of drying content. These curves are used as the basis for the drying characteristic curve. This curve can be explained drying mechanism better by describing the rate changes in the moisture content of the sample $(\mathrm{dx} / \mathrm{dt}$ ) towards the moisture content of the material (X). This study determined the drying rate on the base of formula propose [6].

$$
\frac{d x}{d t}=-k(X-X)
$$

where:

$\mathrm{X}=$ moisture content (dry basis, $\mathrm{g} / \mathrm{g}$ )

$\mathrm{Xe}=$ equilibrium moisture content (dry basis, $\mathrm{g} / \mathrm{g}$ )

$\mathrm{k}=\mathrm{a}$ constant

$\mathrm{t}=$ drying time $(\min )$

\subsection{Effect of Air Temperature on The Derease of Water Content and Drying Rate}

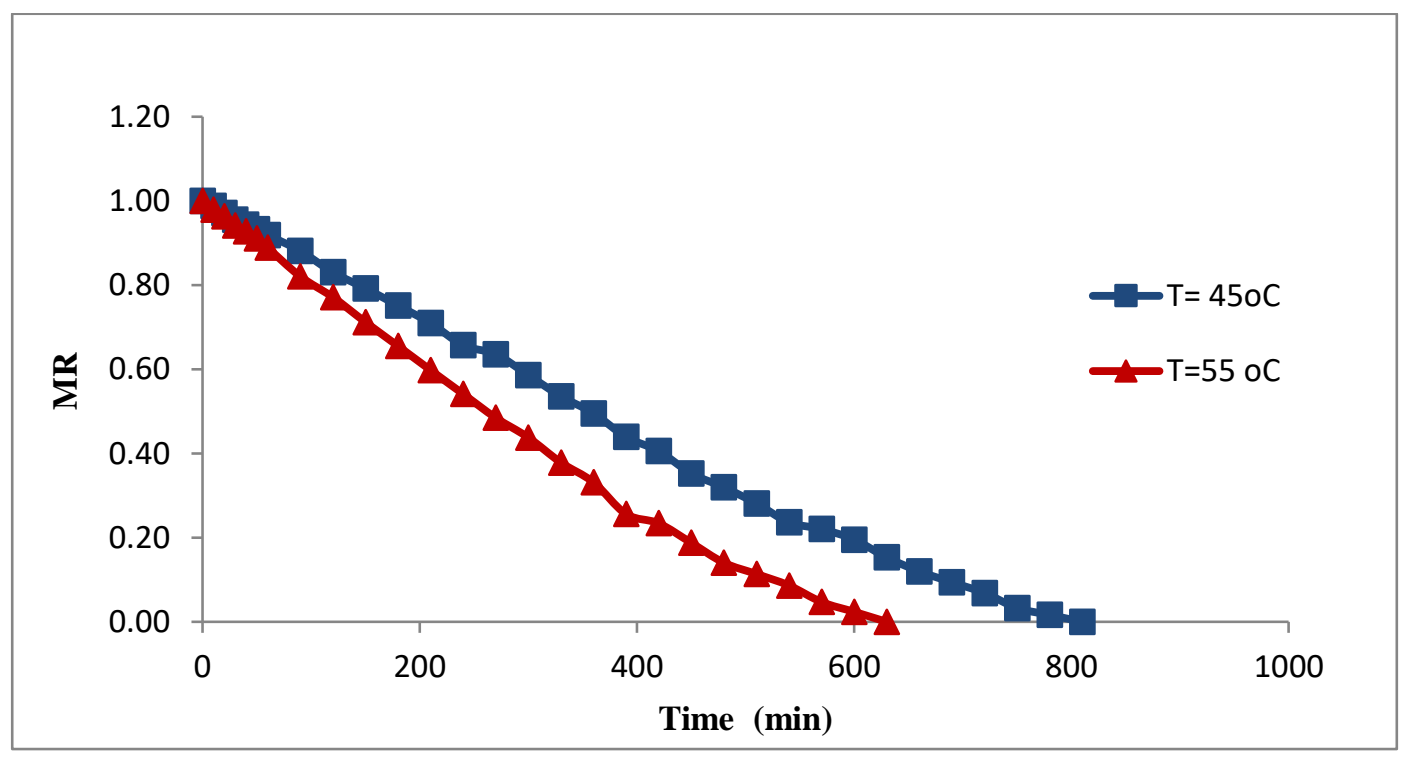

Fig 3. Relationship of MR (Moisture Rasio) vs drying rateat air flow rate of 1,15 m/sandtemperature variation $\left(45\right.$ and $\left.55^{\circ} \mathrm{C}\right)$ 


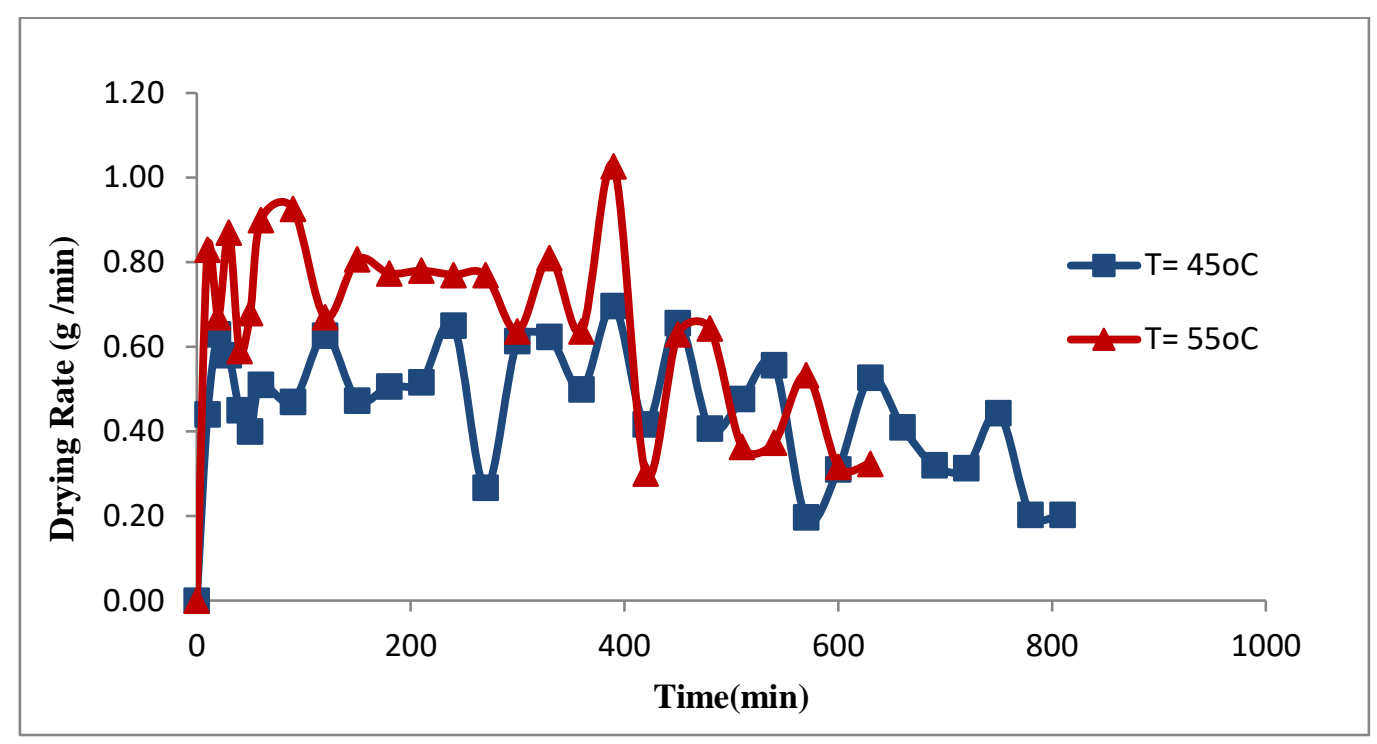

Fig 4.Drying rate vs drying timeat air flow rate of $1,15 \mathrm{~m} / \mathrm{sand}$ temperature variation $\left(45\right.$ dan $\left.55^{\circ} \mathrm{C}\right)$

Figure 3 shows that the drying temperature affects the decrease of material moisture content and the drying rate. At higher temperatures, the moisture content decreases faster and the drying rate also increases. This is due to the air which carries the water vapor, comes out faster from the material surface to the environment compared to the lower drying temperature. The drying with temperature of $45^{\circ} \mathrm{C}$ reaches a constant weight at 750 min while drying with a temperature of $55^{\circ} \mathrm{C}$ reaches a constant weight at 570 minutes. It shows that the drying conditions with the temperature of $55^{\circ} \mathrm{C}$ is better than drying with temperature of $45^{\circ} \mathrm{C}$ with same air flow rate that is $1,15 \mathrm{~m} / \mathrm{s}$.

Figure 4 shows that drying rate at temperature of $55^{\circ} \mathrm{C}$ has higher drying rate compared to the drying rate at temperature of $45^{\circ} \mathrm{C}$, as shown at 390 minutes that temperature of $45 \mathrm{oC}$ has $0,70 \mathrm{~g} / \mathrm{min}$ of drying rate, while the drying rate at temperature of $55^{\circ} \mathrm{C}$ is $1,03 \mathrm{~g} / \mathrm{min}$.

\subsection{Effect of Drying Air Flow Rate on The Decrease of Moisture Content and Drying Rate}

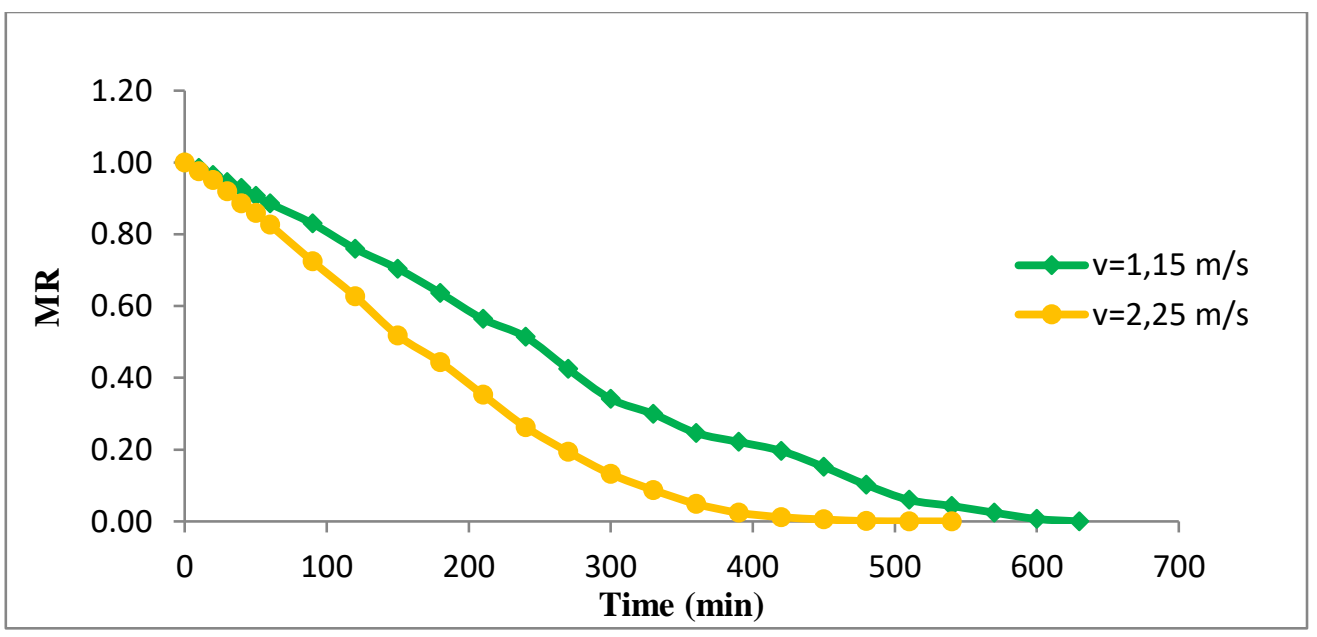


Fig 5. Moisture content vs drying time at $55 \mathrm{oC}$ and air flow rate variation $(1,15$ and 2,25 m/s)

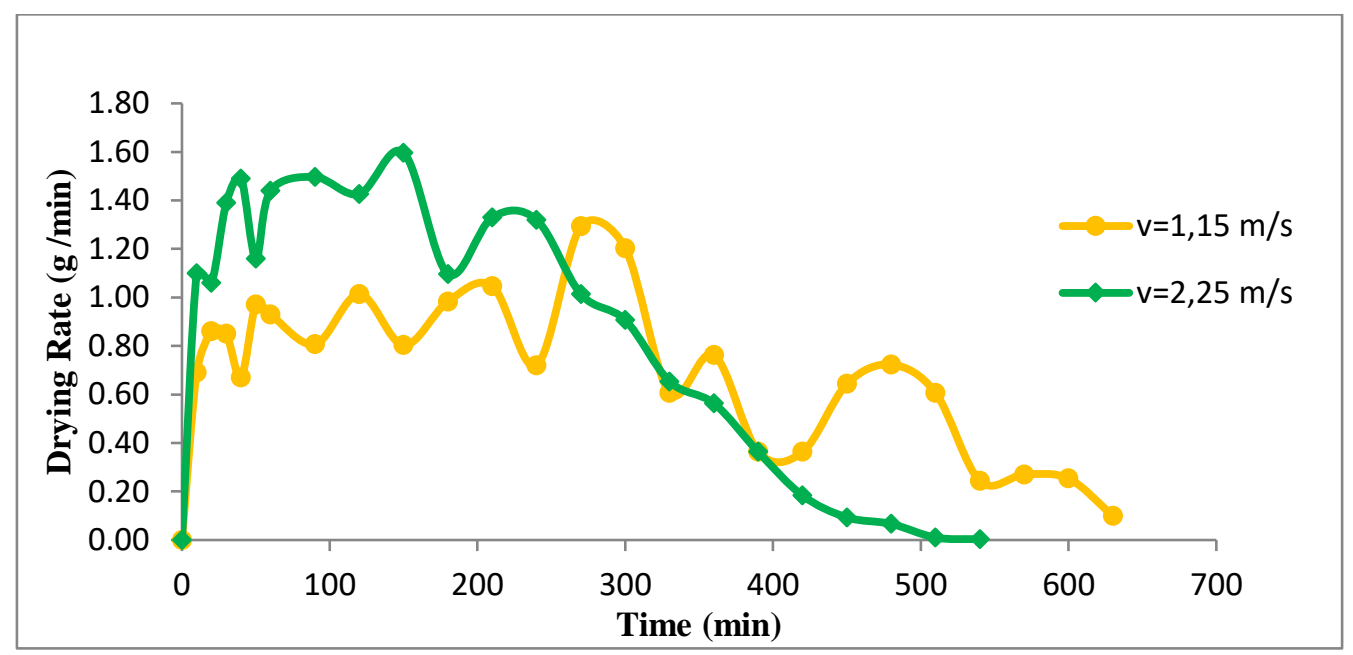

Fig 6. Drying ratevs drying time at $55 \mathrm{oC}$ and air flow rate variation $(1,15$ and $2,25 \mathrm{~m} / \mathrm{s})$

Air flow rate affects the decrease of the material moisture content. At air flow rate of $2.25 \mathrm{~m} / \mathrm{s}$, the decrease in moisture content is faster than at air flow rate of $1.15 \mathrm{~m} / \mathrm{s}$. This is due to the air which carries the water vapor, comes out faster from the material surface to the environment compared to the lower drying air flow rate, at air flow rate of $1.15 \mathrm{~m} / \mathrm{s}$, it reaches equilibrium at $540 \mathrm{~min}$ while at air flow rate of $2.25 \mathrm{~m} / \mathrm{s}$, it reaches equilibrium at $390 \mathrm{~min}$. It shows that the drying operation condition using air flow rate of $2,25 \mathrm{~m} / \mathrm{s}$ is better than drying with the air flow rate of $1,15 \mathrm{~m} / \mathrm{s}$ with the same drying temperature that is $55^{\circ} \mathrm{C}$ [7].

Figure 6 shows the relationship between drying rate with air flow rate variations. At air flow rate of $2,25 \mathrm{~m} / \mathrm{s}$, it has higher average drying compared to the drying rate with air flow rate of $1.15 \mathrm{~m} / \mathrm{s}$. At 150 minutes, the drying rate is $1.60 \mathrm{~g} / \mathrm{min}$ with air flow rate variation of $2,25 \mathrm{~m} / \mathrm{s}$, whereas at air flow rate of $1,15 \mathrm{~m} / \mathrm{s}$, it has drying rate of 0.80 $\mathrm{g} / \mathrm{min}$.

\subsection{Drying Characteristic}

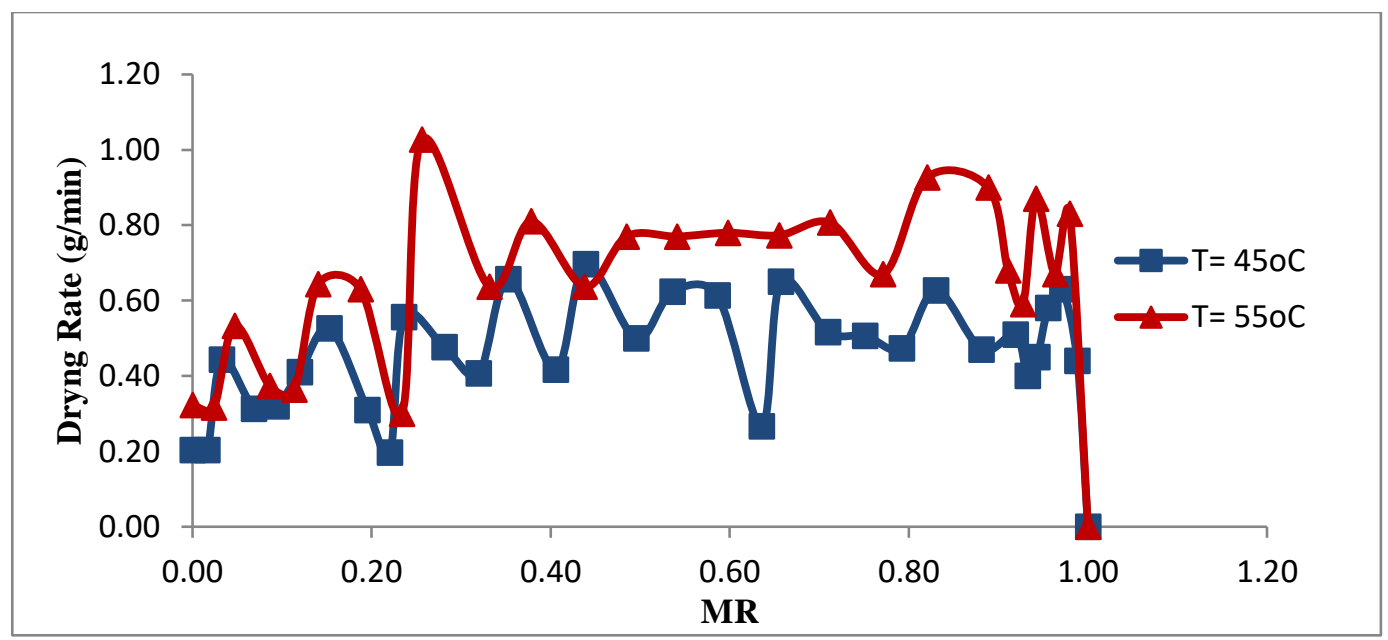


Fig 7. Dying Characteristic Curve with Temperature Variation (45 dan 55oC) and Air Flow Rate (1,15 m/s)

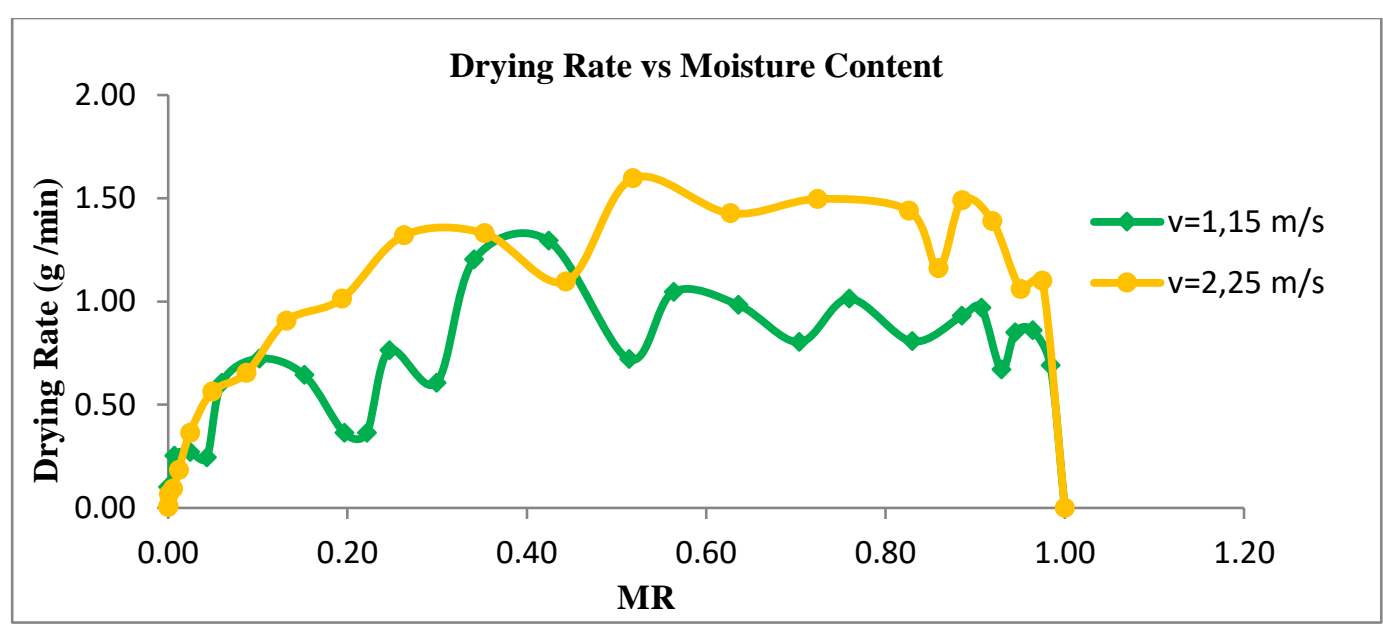

Fig 8.Dying Characteristic Curve with Air Flow Rate Variation (1,15 dan 2,25 m/s) dan Temperature(55oC)

The drying characteristic curve is defined as the drying rate curve vs normalized moisture content as shown in Figure 7 and 8 . The drying characteristic curve is in the form of a parabolic curve over a range of varied temperature and velocity. Figure 7 shows the drying characteristic with temperature variation, and figure 8 shows the drying characteristic with air flow rate variation. Figure 7 indicates that the temperature of $55^{\circ} \mathrm{C}$ consists three drying period, while the temperature of $45^{\circ} \mathrm{C}$ are found with only two drying periods. Although there is a little fluctuation at figure 8 , it tends to show that the drying characteristic has three periods.

Keech et al. (1995) and Ryan et al. (2003) in R. Hasibian, 2010 reported that there were two periodfound in a drying process, namely the constant drying rate period (constant rate drying period) and the decreases drying rate period (falling drying rate period) that goes fast and slow. Yet according to Chen in the journal reported by Polat (1987) in addition to a second period which should have been reported above there is also another very important period, that period is the increasing drying rate period, because half of the drying process occurs in this period.

\section{Conclusions and Suggestions}

The tray dryer has proven to be capable of dryingGarcinia atroviridis from $90 \%$ of moisture content to less than $10 \%$.Effect of drying temperature and air flow rate is very evident in the removal of moisture content. In various temperature of drying medium, at $45^{\circ} \mathrm{C}$ the drying characteristic consists of an increasing drying rate and decreasing drying rate periods, while the constant drying rate is not visible due to its fluctuation, however at drying temperature of $55^{\circ} \mathrm{C}$, it consists of three periods which are the increasing drying rate, constant drying rate, and decreasing drying rate, likewise with the air flow rate variation, consists of three drying period for air flow rate of 1,15 dan $2,15 \mathrm{~m} / \mathrm{s}$

\section{References}

[1] Amran, Adel.A., Zakaria, Zaiton., Othman, Faizah dan Morat, Paden, Effect of Garcinia Atroviridis on Oxidative Stress and Atherosclerotic Changes in Experimental Guinea Pigs, American Journal of Pharmacology and Toxicology 5 (2010) 65-70.

[2] Isnaini, Muhammad, Menggali Potensi Tanaman Asam Gelugur, http://www.sungai-kuantan.com, 2014accessed on 23 August 2015.

[3] Kakomole, Jeane Blandina, Karakteristik Pengeringan Biji Pala (Myristica Fragrans H)Menggunakan Alat Pengering Energi Surya Tipe Rak, Universitas Sam Ratulangi, 2012. 
[4] Boulevard, Folsom, Method for Determining Moisture content by Oven Drying. Department of Transportation Engineering Service Center, 1999.

[5] Kemp, I.C., Christran, F.B., Laurent, S., Michel, A.R., Carda, E.G., Evangelos, T., Alberto, A.S., Cathenne, B.B., Jean, J.B. \& Mathhues, K. 2001. Methods for processing experimental drying kinetics data. Drying technology, 19 (1): 15-34.

[6] Mujumdar, Arun S, Industrial Transfer Processes, National University of Singapore, 2011.

[7] Rosdanelli, H. \& Daud, W.R.W. 2003. The effects of temperature and velocity on drying rate in superheated steam drying of EFB fibers. Proc. 3rd Asia-Pacific Drying Conference, Bangkok. hal. 619 - 626.

[8] Rosdanelli H., 2010, Karakteristik Alat Pengering Kombinasi Energi Surya dan Tapis Molekular untuk Pengeringan Bunga Rosela . Prosiding Seminar Nasional Teknik Kimia. Medan ISSN 1693-4881. 